\title{
Vertical Single-Effect Diffusion Solar Still Coupled with a Tilted Wick Still: An Experimental Study
}

\author{
Mohd Zaheen Khan \\ Department of Mechanical Engineering, Jamia Millia Islmia, New Delhi-110025
}
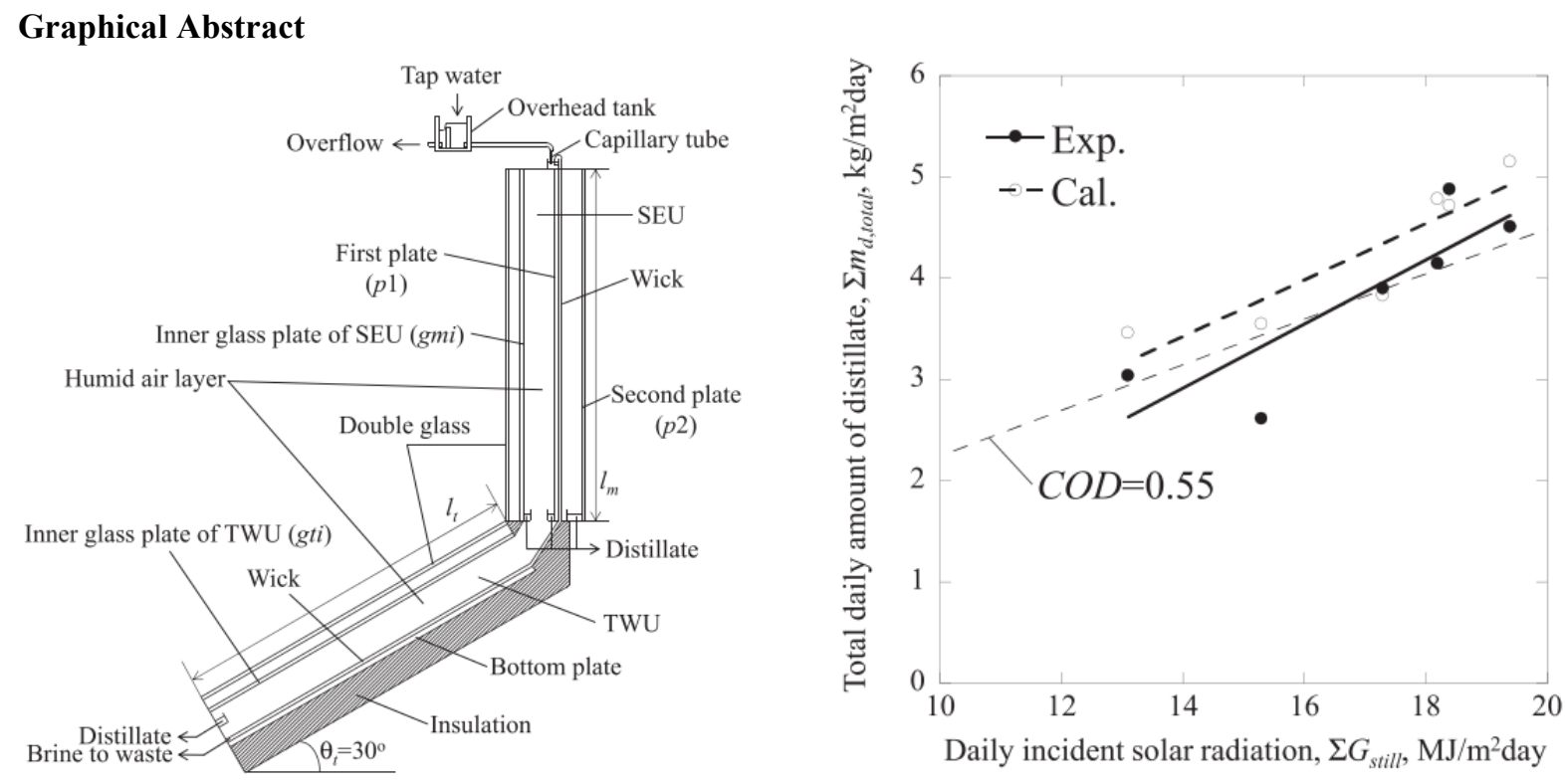

\begin{abstract}
A single-effect diffusion still, instead of a multiple-effect diffusion (MED) still, combined with a tilted wick (TW) still was investigated experimentally under actual weather conditions to investigate whether the natural convection can transport the vapor from the TW still to an MED still adequately. It was found that the single-effect still can be heated by vapor from the TW still and solar radiation absorbed on the single-effect still. From the experiments in summer and autumn, it was found that a MED still can be heated in both seasons whether the MED still absorbs solar radiation directly or not. The experimental results agreed with the calculation results. The total daily amount of distillate, $\Sigma \mathrm{m}_{\mathrm{d} \text {,total, }}$ did not correlate with the daily horizontal solar radiation, $\Sigma \mathrm{G}_{\text {day }}$, but strongly correlated with daily solar radiation incident on the still, $\Sigma \mathrm{G}_{\text {still }}$. The maximum of $\Sigma \mathrm{m}_{\mathrm{d}, \text { total }}$ obtained in experiments was about 4.88 $\mathrm{kg} / \mathrm{m}^{2}$ day when $\Sigma \mathrm{G}_{\text {day }}$ and $\Sigma \mathrm{G}_{\text {still }}$ were 13.6 and $18.4 \mathrm{MJ} / \mathrm{m}^{2}$ day, respectively
\end{abstract}

Keywords: Outdoor experiment, Solar still, Solar desalination, Tilted wick, Multiple-effect

DOI: $10.7176 /$ APTA/84-01

Publication date:August $31^{\text {st }} 2021$

\section{Introduction}

Solar powered stills come in many types, but multiple-effect diffusion stills (MED stills) and tilted wick stills (TW stills) are two of the most common. Both types of still have a wick from which the water evaporates. TW stills (configured much like the TW unit (TWU) in Fig. 1) basically involve a wick and transparent cover, and salt water flows into the wick continuously. Solar energy serves to heat the salt water and the generated vapor condenses on the transparent cover resulting in distilled water. MED stills (configured much like the ME unit (MEU) in Fig. 1) utilize several parallel plates, each with its own evaporating wick. The bare surface of each plate serves as both heating and condensing surface, and the surface in contact with the wick serves as an evaporating surface. Salt water flows into the wicks. Plates are positioned with narrow gaps of a few millimeters. The first plate receives solar radiation which in turn heats and evaporates the salt water in the wick placed on the first plate. Condensation of the resulting vapor occurs on the next plate. This condensation releases latent energy which, along with the radiative and conductive thermal energy, serves to evaporate the salt water in the second plate's wick. The performance of MED stills tends to be much more efficient than single-effect stills, since evaporation and condensation are repeated using the same energy. This type of still was proposed by Dunkle [1] in 1961, and he constructed a five-effect vertical MED still combined with a solar absorber, and performed experiments as well as numerical analysis. Inclined downward-heating MED still, in which distillation occurs downwards repeatedly, was proposed by Cooper and Appleyard [2], and they constructed and tested a three-effect MED still. Elsayed et al. 
[3] constructed a three-effect vertical MED still heated by a heat transfer bench. They also performed numerical analysis and reported about the effects of the heating water temperature and the cooling water temperature on the distillate productivity. Tsumura et al. [4] constructed and tested a ten-effect downward-heating MED still, and reported about the relationship between the temperature of a solar absorbing plate and the distillate productivity. Inclined upward-heating MED still, in which distillation occurs upwards repeatedly, was proposed by Tanaka et al. [5]. They constructed a seven-effect MED still combined with an inverted reflector and a five-effect MED still combined with a heat pipe solar collector. They reported that the experimental and theoretical results are in good agreement. Kiatsiriroat et al. [6] experimentally and numerically analyzed a vertical MED still combined with a solar collector, and reported that the distillate productivity increases with an increase in the ratio of the evaporating surface area to the solar collector area. Toyama et al. [7] proposed an upward-heating MED still, in which the lowermost partition plate absorbs solar radiation passing through

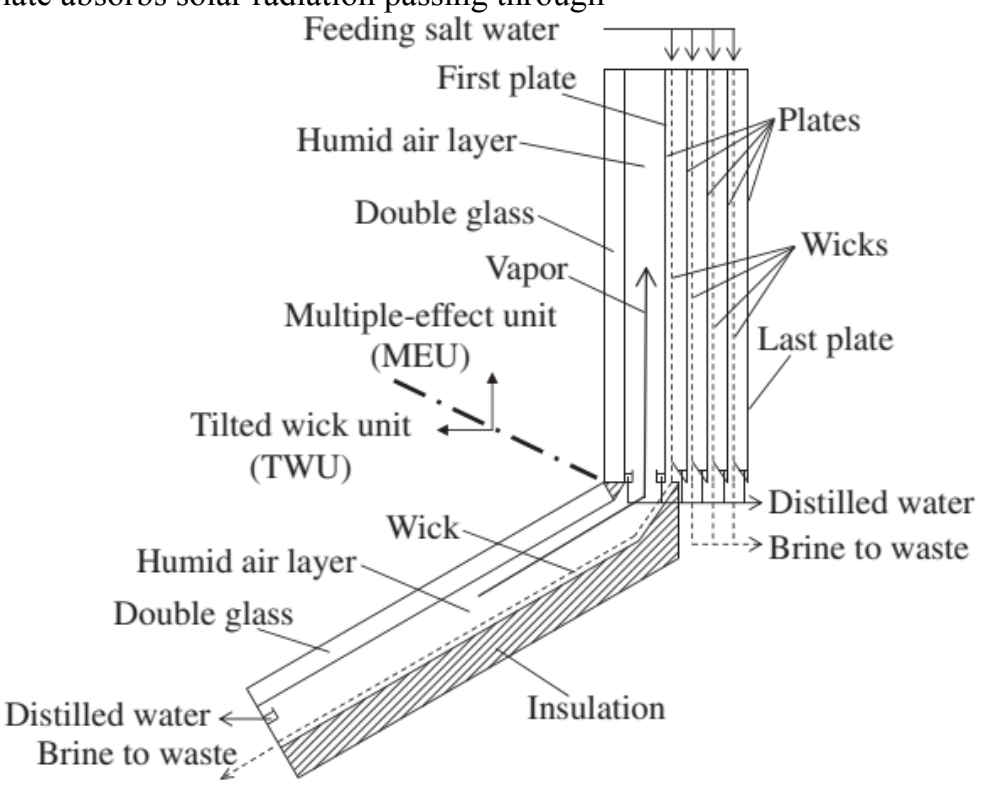

Fig: 1

all the upper plates. Ouahes and Le Goff [8] constructed a three-effect downward-heating MED still and tested it under actual and artificial radiation. Okamura et al. [9] analyzed six-effect and seven-effect downward-heating MED stills. They reported that the feed rate of saline water has to be controlled according to the temperature of the first plate, and it is important to feed saline water to wicks uniformly. Tiwari et al. [10] numerically analyzed an upward-heating MED still, and they reported about the effect of various parameters, such as still length, water flow rate and inclination of the still on the distillate productivity. Ohshiro et al. [11] proposed a downward-heating MED still utilizing hydrophobic PTFE net sandwiched between an evaporating and a condensing wick to decrease the distance between plates. Bouchekima et al. [12] analyzed a three-effect downward-heating MED still numerically and experimentally, and they reported that the distillate productivity can be increased with an increase in the inlet temperature of feed water as well as the intensity of solar radiation. Yeh and Ho [13] proposed an upward-heating MED still similar to the still proposed by Toyama et al. [7]. In the still, several tiny weirs were used to hold the water on the plates. A vertical MED stills coupled with a basin type still [14], a heat pipe solar collector [15] and a flat plate solar collector [16] were proposed and tested, and the results shows that the distance between plates can be decreased significantly by setting the plates vertically. Fukui et al. [17] experimentally and numerically analyzed a downward-heating MED still which can be floated on water surface for maritime lifesaving. Nosoko et al. [18] numerically analyzed a vertical MED still to produce highly concentrated seawater. Chong et al. [19] proposed a vertical MED still combined with a vacuum-tube collector and heat pipe. In the still, the plates were bent to avoid contamination of distilled water and peel-off of the wicks. Huang et al. [20] constructed and tested a spiral vertical MED still combined with a vacuum-tube collector and heat pipe, and the distillate productivity of the still is highest among the MED stills which have been studied. These studies were reviewed by Rajaseenivasan et al. [21].

\section{Proposed still}

A vertical MED still combined with a TW still was suggested in a past paper [22]. An outline of the still is shown in Fig. 1. TWU was positioned under MEU. Each unit has double glass for insulation. The humid air layers next to the double glass of both units are connected to allow natural convection to transport the vapor from TWU to the layer of evaporated moisture of MEU. Salt water flows into the wicks of all but the last plate. The wick attached to the first plate of MEU is connected to the wick of TWU so that the salt water released from the wick of the first 
plate reaches to the wick of TWU. Concentrated salt water is released from the base of TWU and the base of the wicks of all plates with the exception of the first and last plates in MEU.

Salt water in the wick of TWU is heated and evaporated by solar radiation, and the condensation occurs on the inner surface of the double glass of each unit. Condensation of the remaining vapor occurs on the first plate of MEU, and the solar radiation directly absorbed as well as the latent heat of the vapor becomes the energy source for MEU.

In a past paper [22], the basic performance of the still was theoretically calculated. In this paper, an experimental device was constructed and tested in outdoor experiments at National Institute of Technology, Kurume College, Japan $\left(33.2^{\circ} \mathrm{N}\right.$ latitude and $130.2^{\circ} \mathrm{E}$ longitude). Here, to investigate whether natural convection can transport water vapor from TWU to MEU adequately, a single-effect unit was used for MEU in the experiments.

\section{Experimental apparatus and procedure}

Fig. $2 \mathrm{a}$ and $\mathrm{b}$ shows a photo and a back view of the experimental device, respectively, and Fig. 3 shows an outline of the experimental device. TWU was made from a bottom plate (stainless steel plate of $1 \mathrm{~mm}$ in thickness) and double glass which areas were about $0.348 \mathrm{~m}^{2}(0.59 \mathrm{~m} \times 0.59 \mathrm{~m})$, and the wick was placed above the bottom plate. Black cotton flannel (thickness is about $0.5 \mathrm{~mm}$ and evaporating area was about $\left.0.336 \mathrm{~m}^{2}(0.58 \mathrm{~m} \times 0.58 \mathrm{~m})\right)$ was used for the wick of TWU. The bottom of TWU was insulated with a urethane foam board of about $50 \mathrm{~mm}$ in thickness, and the urethane foam board was covered with plywood of about $10 \mathrm{~mm}$ in thickness. The angle of the TWU, $\theta_{\mathrm{t}}$, was fixed at $30^{\circ}$ from horizontal which is almost the same as the latitude of the experimental site. A single-effect unit was constructed instead of MEU as mentioned above.
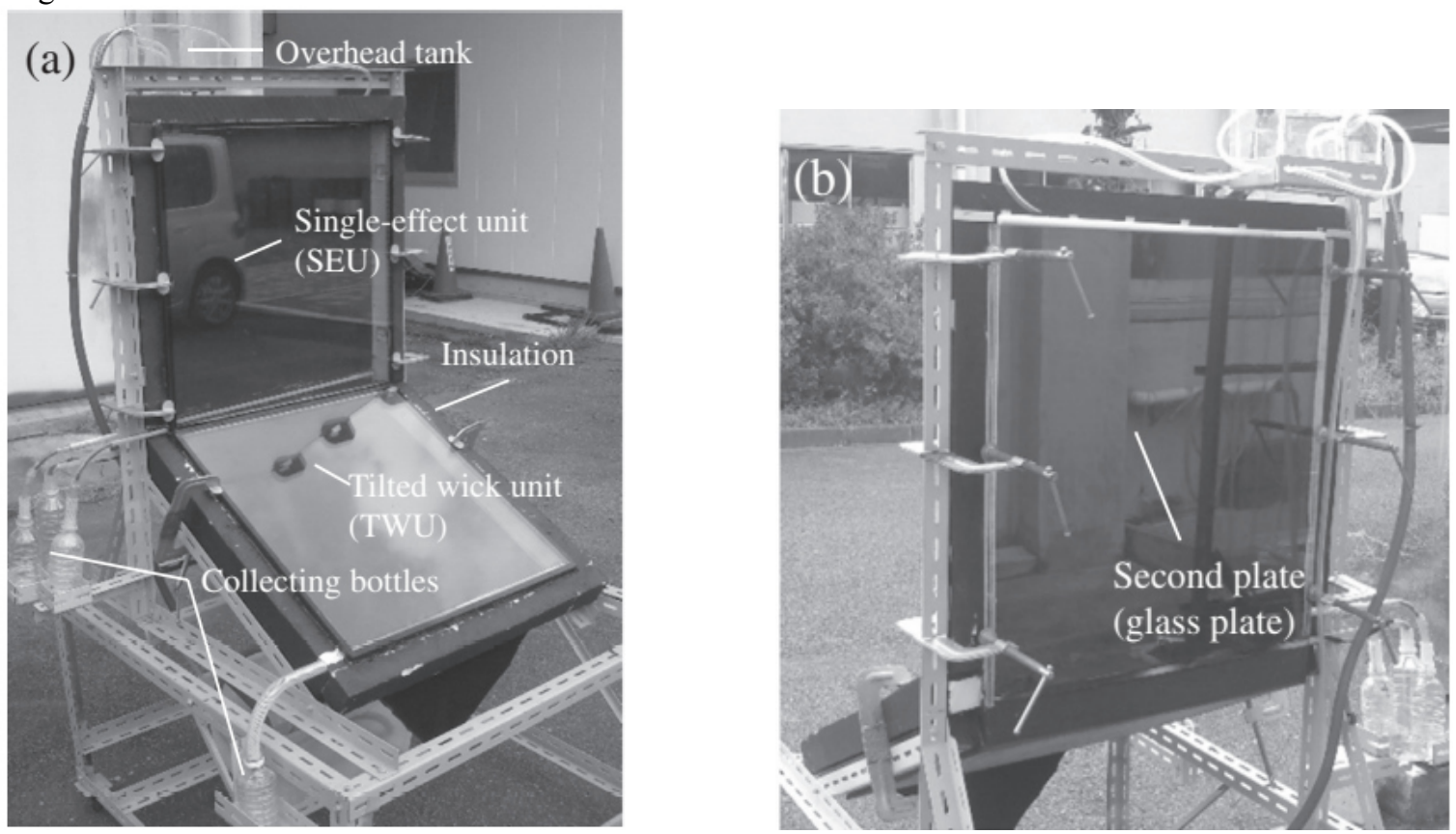

Fig: 2

Therefore, this unit is called SEU below. SEU was made from double glass, the first plate (stainless steel plate of $1 \mathrm{~mm}$ in thickness) and the second plate which areas were about $0.348 \mathrm{~m}^{2}(0.59 \mathrm{~m} \times 0.59 \mathrm{~m})$. The front of the first plate was blackened. A glass plate ( $5 \mathrm{~mm}$ in thickness) was used for the second plate to observe the inside of the SEU. The thickness of the humid air layers of TWU and SEU were fixed at $60 \mathrm{~mm}$ and $50 \mathrm{~mm}$, respectively to allow for sufficient natural convection in all of the humid air layers. The walls of the humid air layers were made from $10 \mathrm{~mm}$-thick acrylic plates and insulated with a urethane foam board of about $50 \mathrm{~mm}$ in thickness. Each glass plate of the double glass was $4 \mathrm{~mm}$ in thickness and a $6 \mathrm{~mm}$-thick air layer was sandwiched and sealed between the glass plates. The aperture area of each double glass was about $0.336 \mathrm{~m}^{2}(0.58 \mathrm{~m} \times 0.58 \mathrm{~m})$. The distance between the first and second plate was $10 \mathrm{~mm}$, and to avoid vapor leakage an approximately $9 \mathrm{~mm}$-thick urethane foam bar was sandwiched at the top end between them. To the rear surface of the first plate, the wick (about $0.5 \mathrm{~mm}$ thick cotton flannel) which evaporating area was approximately the same as the wick of TWU was attached by adhesive and the wicks of the first plate and TWU were connected. Both TWU and SEU were clamped to prevent vapor leakage. As mentioned below, since vapor leakage had occurred in the earlier experiments in spite of the fact that each unit was clamped; each double glass was attached to the walls with silicone sealant. Collecting channels were attached at the underside of each condensing surface. 


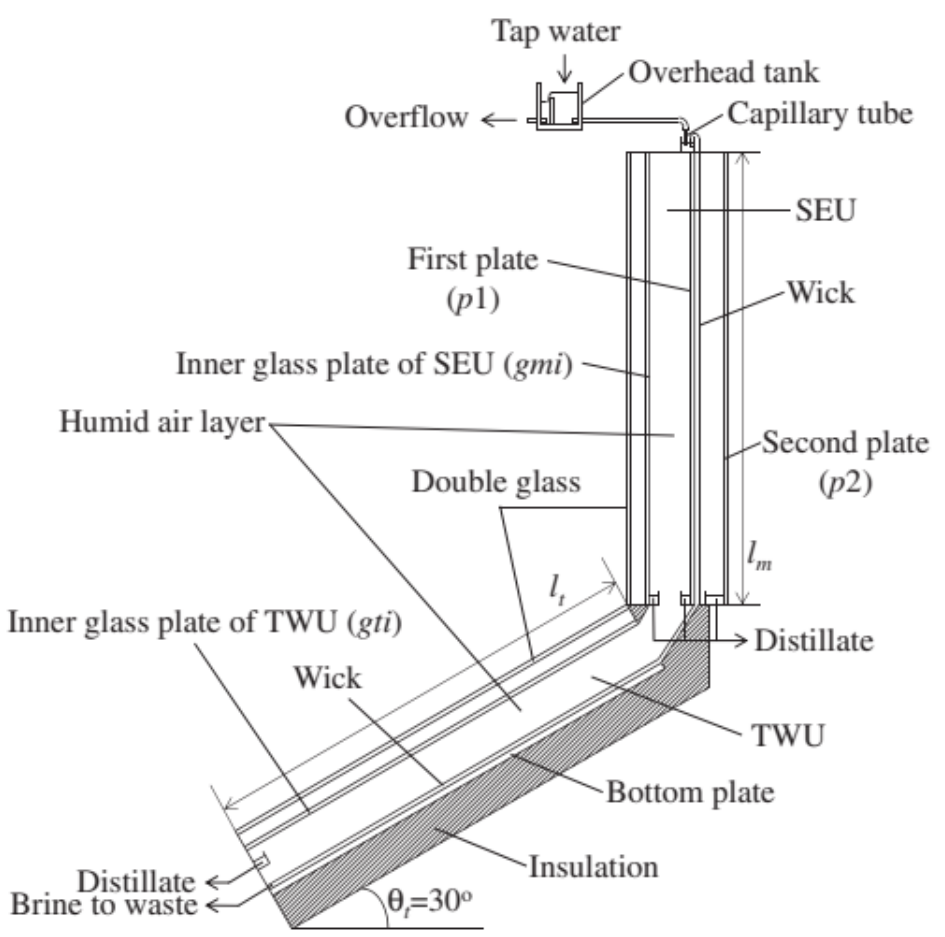

Fig: 3

The still was set on the experimental site facing south. Tap water was used as feed water instead of salt water. The rate of feed water was adjusted by changing the water head of an overhead tank and the length of a capillary glass tube. The rate of feed water was set at about twice as fast as the sum of evaporation rates from the wicks of the first plate and TWU, which was calculated with the assumption that the solar radiation would be constant at the day's peak. The amounts of the distillate on each condensing surface as well as discharged water from the bottom of the wick of TWU were measured with collecting bottles and a digital scale (UX4200H, Shimadzu Co., operating range and accuracy were $0 \mathrm{~g}$ to $4200 \mathrm{~g}$ and $\pm 0.01 \mathrm{~g}$ ) at about 2-h intervals. A pyranometer (MS-601, EKO Instruments Co., operating range and accuracy were $0 \mathrm{~W} / \mathrm{m}^{2}$ to $1400 \mathrm{~W} / \mathrm{m}^{2}$ and $\pm 2.5 \%$ ) was used to measure global horizontal solar radiation at 1-min intervals. An alcohol thermometer (operating range and accuracy were $-20{ }^{\circ} \mathrm{C}$ to $50{ }^{\circ} \mathrm{C}$ and about $\pm 1{ }^{\circ} \mathrm{C}$ ) was used to measure ambient air temperature at about 2 -h intervals.

The measurement errors for solar radiation and ambient air temperature would be about $\pm 2.5 \%$ and $\pm 1{ }^{\circ} \mathrm{C}$ due to inaccuracy of measuring devices. The measurement errors for the amounts of the distillate and the discharged water would be about $\pm 1 \%$ due to inaccuracy of measuring procedure and the digital balance.

\section{Theoretical analysis}

The method to calculate the distillate productivity of the still was presented in a past paper [22]. The difference between the calculations in this paper and one in a past paper is described below. Global horizontal solar radiation $\mathrm{G}_{\mathrm{h}}$ was determined by calculating direct radiation $\mathrm{G}_{\mathrm{dr}}$ with Bouguer's equation and diffuse radiation $\mathrm{G}_{\mathrm{df}}$ with Berlage's equation, and the transmittance of atmosphere $\tau_{\text {atm }}$ was assumed to be constant at 0.7 in a past paper [22] . In the experiments, $G_{d r}$ and $G_{d f}$ could not be measured separately, and only $G_{h}$ was measured. Therefore, $G_{d r}$ and $\mathrm{G}_{\mathrm{df}}$ was calculated from the measured $\mathrm{G}_{\mathrm{h}}$ and a solar constant $\mathrm{I}_{\mathrm{o}}$ of $1370 \mathrm{~W} / \mathrm{m}^{2}$ by solving Eq. (3) respect to $\tau_{\mathrm{atm}}$ and substituting the calculated $\tau_{\mathrm{atm}}$ to the equations for $\mathrm{G}_{\mathrm{dr}}$ and $\mathrm{G}_{\mathrm{df}}[23]$.

$$
\begin{gathered}
G_{d r}=I_{o} \sin \varphi \cdot \tau_{a t m}^{1 / \sin \varphi} \\
G_{d f}=\frac{1}{2} I_{o} \sin \varphi \cdot\left(1-\tau_{a t m}^{1 / \sin \varphi}\right)\left(1-1.4 \ln \tau_{a t m}\right) \\
G_{h}=G_{d r}+G_{d f}
\end{gathered}
$$

\section{Results and discussion}

Experimental and calculation results of (a) hourly variations of distillate production rate, $m_{d}$, and (b) daily amount of distillate, $\Sigma m_{d}$, on condensing surfaces on 29 June 2015 (around the summer solstice) are shown in Fig. 4. The total daily amount of distillate (Total) was shown in $1 / 2$ scale in Fig. 4 b. 

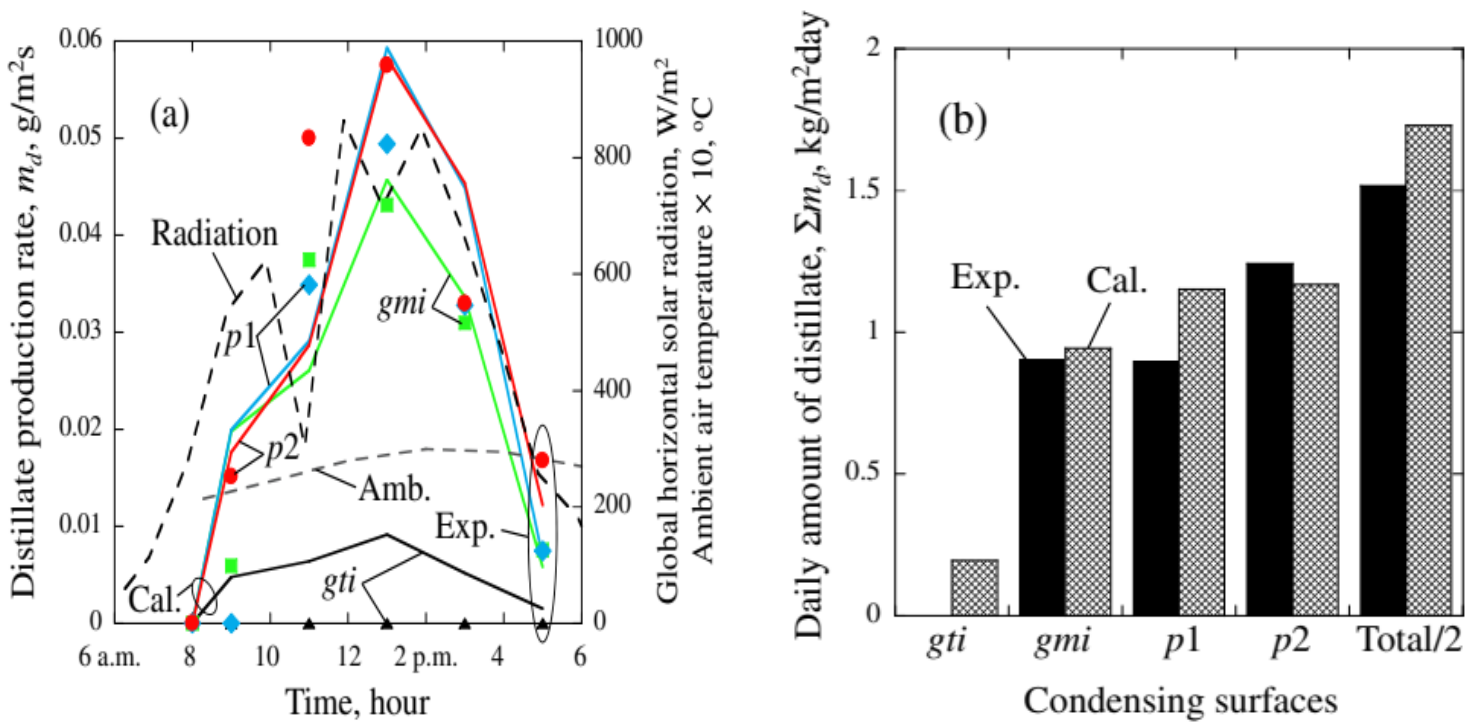

Fig: 4

Global horizontal solar radiation (Radiation) and ambient air temperature (Amb.) are also shown in Fig. 4a, and ambient air temperature is shown in tenfold scale. In Fig. 4a, experimental and theoretical results of $m_{d}$ are shown as plots and lines, respectively. Here, as shown in Fig. 3, gti and gmi show the inner condensing surfaces of the double glass of TWU and SEU, respectively, and $p 1$ and $p 2$ show the condensing surfaces of the first and second plates, respectively. In this paper, $m_{d}$ and $\Sigma m_{d}$ are shown per aperture area of the double glass of TWU. It was a partly cloudy day, and the experiment was started at 8 a.m. $m_{d}$ shows a similar trend with global horizontal solar radiation and peaks at around 1 p.m. Evaporated vapor from TWU mainly condensed on gmi and $p 1$. The reason is as follows: hourly variations of the global horizontal solar radiation (Radiation), and solar radiation absorbed on the wick of TWU (Wick of TWU) and the first plate of SEU ( $p 1)$ are shown in Fig. 5. On this day, the solar elevation angle was very large, and solar radiation could scarcely be absorbed on $p 1$. Therefore, the absorbed solar radiation on $g t i$ was greater than for $g m i$ and $p 1$. As a result, the temperature of gti was greater than for $g m i$ and $p 1$, and not much condensation took place on gti. A reasonable amount of $m_{d}$ and $\Sigma m_{d}$ was observed on $p 2$.

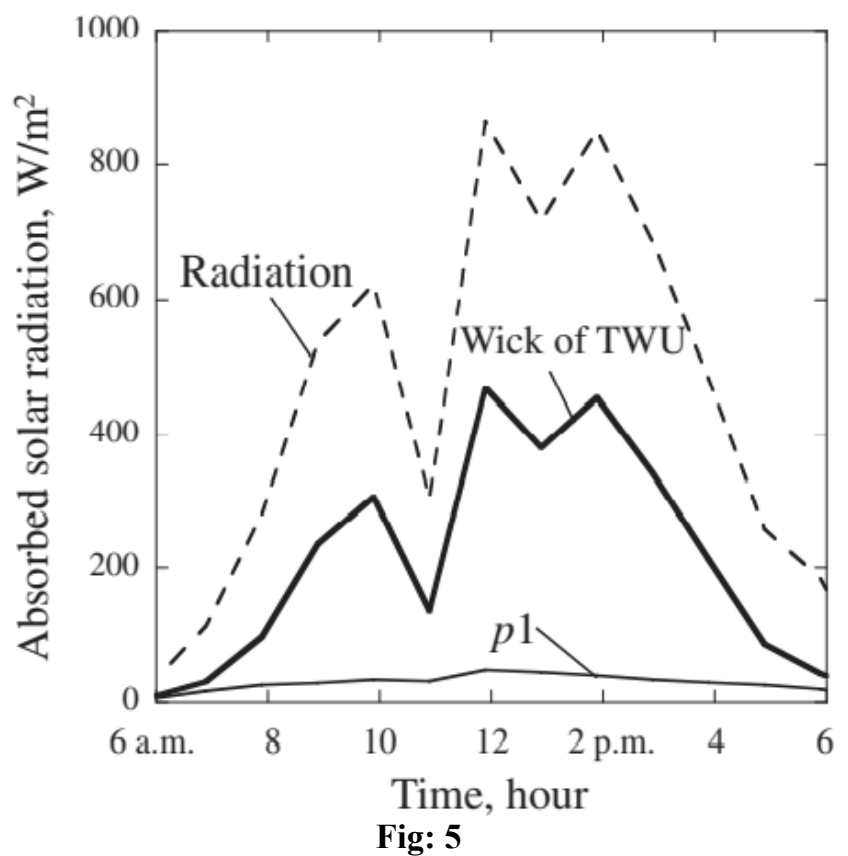

Therefore, it was found that natural convection can transport the vapor from TWU to SEU to use it as a heat source for SEU when the solar radiation can scarcely be absorbed on $p 1$. Here, almost no distillate was observed on gti during the experiment due to vapor leakage from the clearance between the double glass and the walls in spite of the fact that TWU was clamped. Therefore, each double glass was attached to the walls with silicone sealant after this experiment to prevent vapor leakage. The experimental and calculation results on 19 September 
2015 (around the autumnal equinox) are shown in Figs. 6 and 7. It was a very clear day and the experiment was started at 8 a.m. On this day, the solar elevation angle was smaller than in June, and pl was able to absorb a larger amount of solar radiation than in June (Fig. 7).
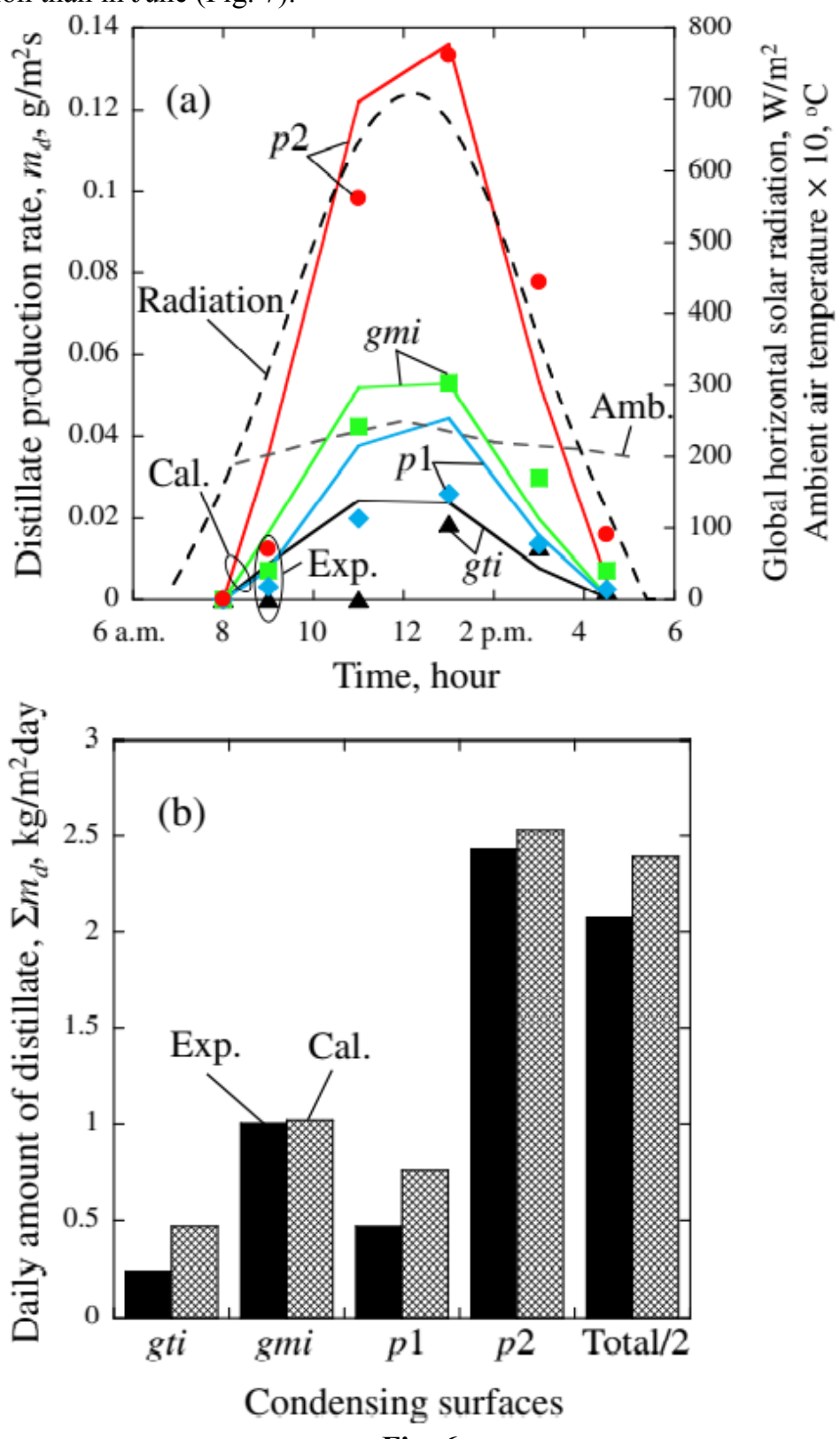

Fig: 6

The vapor from TWU was condensed on all the condensing surfaces of the humid air layer ( $g t i$, gmi and $p l$ ). The distillate on $g m i$ was the greatest of these three inner surfaces since solar radiation absorbed is smallest and thus temperature was lowest for gmi. The distillate on $p 1$ was less than in the summer experiment due to the higher temperature. However, the distillate on $p 2$ was larger than in summer, since $p 1$ was able to absorb solar radiation directly.

From the experiments in summer and autumn, it was found that MEU of the still can be heated adequately in both cases whether the first plate of MEU absorbs solar radiation directly or not. The experimental results agreed with the calculation results on both days. This indicates that the theoretical analysis [22] can be applied to all seasons. 


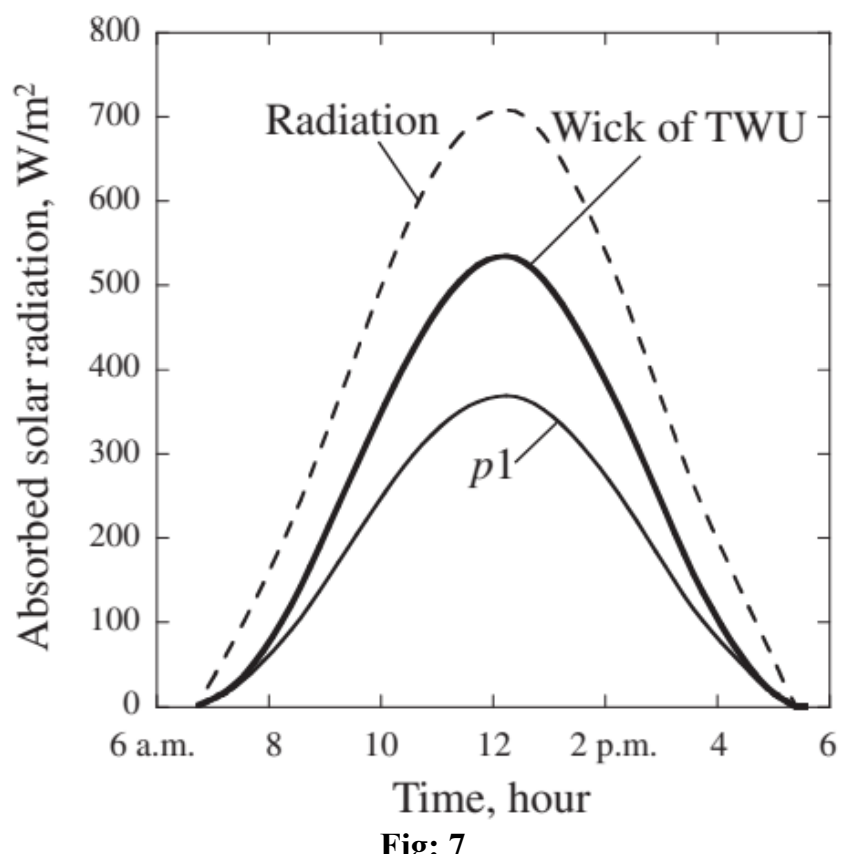

Fig: 7

Experimental and calculation results of the total daily amount of distillate, $\Sigma m_{d, t o t a l}$, versus daily horizontal solar radiation, $\Sigma G_{d a y}$, are shown in Fig. 8. The experiments were performed from June to September 2015. Here, $\Sigma G_{d a y}$ was shown as the cumulative value of global horizontal solar radiation for the experimental period of each day. No correlation between $\Sigma G_{d a y}$ and $\Sigma m_{d, t o t a l}$ was observed since the solar radiation which can be received on the still depends not only on horizontal solar radiation but also on the solar elevation angle. Therefore, the daily incident solar radiation, $\Sigma G_{\text {still }}$, was calculated using the following equations:

$$
\begin{gathered}
\sum G_{\text {still }}=\int_{t_{\text {start }}}^{t_{\text {end }}} w_{s}\left[G_{d r}\left\{I_{t} \cos \theta_{t}+\frac{\left(I_{t} \sin \theta_{t}+I_{m}\right) \cos \varphi}{\tan \varphi}\right\}+G_{d f}\left(I_{t}+0.5 I_{m}\right)\right] d t / A_{\text {eff }} \\
A_{\text {eff }}=w_{s} x \sqrt{\left(I_{t} \cos \theta_{t}\right)^{2}+\left(I_{t} \sin \theta_{t}+I_{m}\right)^{2}}
\end{gathered}
$$

$\Sigma m_{\text {d,total }}$ varying with $\Sigma G_{\text {still }}$ is shown in Fig. 9. The linear approximations of the experimental and calculation results are also shown in Fig. 9.

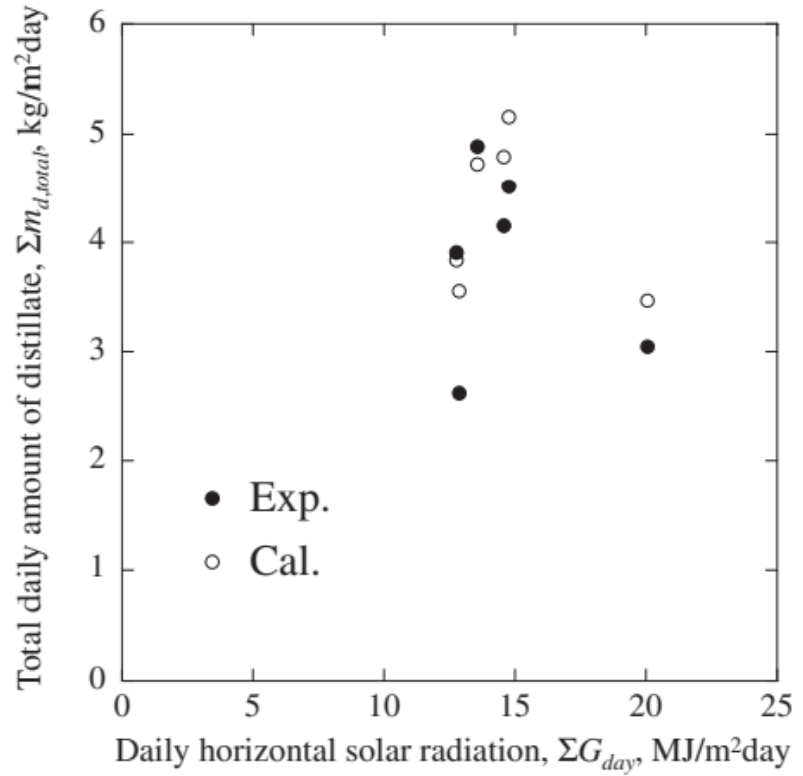

Fig: 8 


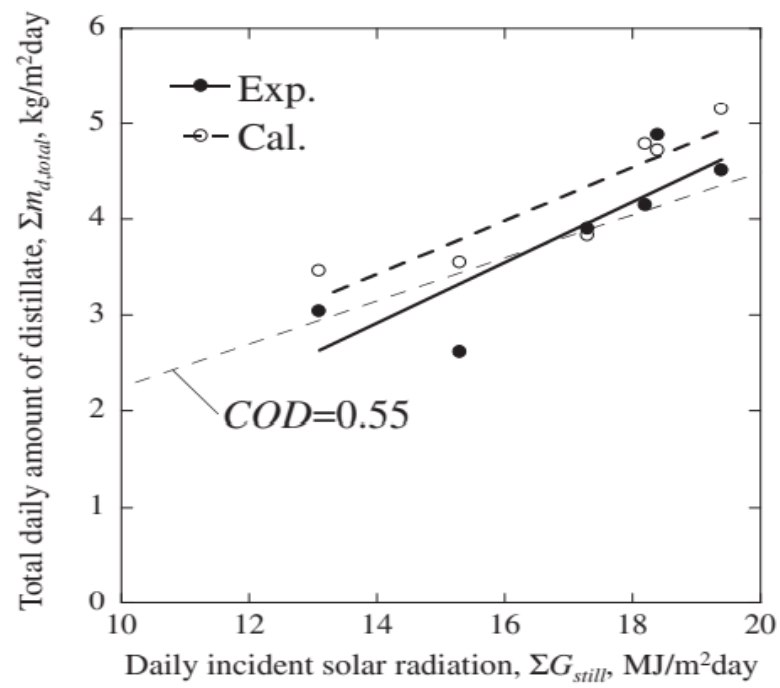

Fig: 9

A strong correlation between $\Sigma G_{\text {still }}$ and $\Sigma m_{\text {d,total }}$ was observed, and $\Sigma m_{d, \text { total }}$ increases with an increase in $\Sigma G_{\text {still }}$. The maximum of $\Sigma m_{d, t o t a l}$ obtained in experiments was about $4.88 \mathrm{~kg} / \mathrm{m}^{2}$ day when $\Sigma G_{d a y}$ and $\Sigma G_{\text {still }}$ were 13.6 and $18.4 \mathrm{MJ} / \mathrm{m}^{2}$ day, respectively. The coefficient of distillation (COD) can be defined by the following equation:

$$
\text { COD }=\frac{\sum m_{d, t o t a l} H_{f g}}{\sum G_{s t i l l}}
$$

The mean value of COD was 0.55. In Fig. 9 , a line which COD is constant and 0.55 is also shown. A line which COD is constant should pass the origin where both values of $\Sigma m_{d, t o t a l}$ and $\Sigma G_{\text {still }}$ are zero. Almost all the experimental results corresponded to this line. However, in general, COD would tend to be higher in summer than in autumn since more energy can be recovered on $p 1$ (see Figs. $4 \mathrm{~b}$ and $6 \mathrm{~b}$ ). Further, COD would tend to increase with an increase in daily solar radiation and ambient air temperature since the ratio of the heat transfer rate by mass transfer to the total heat transfer rate increases with an increase in the mean temperature of the evaporating and condensing surfaces. In this study, obtained results were not sufficient to evaluate these effects on COD. However, the mean value of COD $(0.55)$ would be slightly greater than the typical single-effect stills, since the latent heat of condensation was recovered once on $p 1$ in the experimental device. The mean deviation between the experimental and calculation results was about $9.8 \%$.

\section{Nomenclature}

$A_{\text {eff }}=$ aperture area of still, $\mathrm{m}^{2}$

$C O D=$ coefficient of distillation

$G_{d f ;} G_{d r}=$ diffuse and direct solar radiation on a horizontal surface, $\mathrm{W} / \mathrm{m}^{2}$

$G_{h}=$ global solar radiation on horizontal surface, $\mathrm{W} / \mathrm{m}^{2}$

$\Sigma G_{d a y}=$ daily global solar radiation on a horizontal surface, $\mathrm{W} / \mathrm{m}^{2}$ day

$\Sigma G_{\text {still }}=$ daily solar radiation incident on still, $\mathrm{W} / \mathrm{m}^{2}$ day

$g m i, g t i=$ inner surface of double glass of single-effect and tilted wick unit

$H_{f g}=$ latent heat of evaporation of water, $\mathrm{J} / \mathrm{kg}$

$I_{o}=$ solar constant, $\mathrm{W} / \mathrm{m}^{2}$

$l_{m}=$ height of single-effect unit, $\mathrm{m}$

$l_{t}=$ length of tilted wick unit, $\mathrm{m}$

$m_{d}=$ distillate production rate, $\mathrm{kg} / \mathrm{m}^{2} \mathrm{~s}$

$\Sigma_{m d}=$ daily amount of distillate, $\mathrm{kg} / \mathrm{m}^{2}$ day

$\Sigma m_{\text {d,total }}=$ total daily amount of distillate, $\mathrm{kg} / \mathrm{m}^{2}$ day

$p 1, p 2=$ first and second plate

$t=$ time, hour

$t_{\text {start }}, t_{\text {end }}=$ start and end time of experimental period, hour

$w_{s}=$ width of still, $\mathrm{m}$

\section{Greeks}

$\phi, \varphi=$ elevation and azimuth angles of the sun

$\theta_{t}=$ inclination angle of tilted wick unit from horizontal

$\tau_{\text {atm }}=$ transmittance of atmosphere 


\section{Abbreviations}

$M E D=$ multiple-effect diffusion

$M E U=$ multiple-effect unit

$S E U=$ single-effect unit

$T W=$ tilted wick

$T W U=$ tilted wick unit

\section{References}

[1] R.V. Dunkle, Solar water distillation: the roof type still and a multiple effect diffusion still, 5, International Heat Transfer Conference, Int. Developments in Heat Transfer, Univ. Colorado, 1961 895-902 Part.

[2] P.I. Cooper, J.A. Appleyard, The construction and performance of a three-effect, wicktype, tilted solar still, Sun at Work, 12 (1967) 4-8.

[3] M.M. Elsayed, K. Fathalah, J. Shams, J. Sabbagh, Performance of multiple effect diffusion stills, Desalination 51 (1984) 183-199.

[4] K. Tsumura, M. Yamashita, H. Watanabe, H. Inaba, Relation between temperature of solar radiation receiving plate and volume of distilled water by direct solar multiple effect distillers, Bull. Jpn. Soc. Sea Water Sci. 39 (3) (1985) 129-135.

[5] K. Tanaka, H. Okamura, M. Kan, K. Watanabe, A fundamental study of the performance of a multiple effect solar still (2nd report, experimental analysis on the upward heating type still under the actual outdoor insolation), Trans. Jpn. Soc. Mech. Eng. B 53 (1987) 3771-3779.

[6] T. Kiatsiriroat, S.C. Bhattacharya, P. Wibulswas, Performance analysis of multiple effect vertical still with a flat plate solar collector, Solar \& Wind Technology 4 (4) (1987) 451-457.

[7] S. Toyama, T. Aragaki, H.M. Salah, K. Murase, Dynamic characteristics of a multistage thermal diffusion type solar distillor, Desalination 67 (1987) 21-32.

[8] R.C. Ouahes, P.J. Le Goff, A hardy, high-yield solar distiller of brackish water, Desalination 67 (1987) 43-52.

[9] H. Okamura, K. Tanaka, K. Watanabe, Study on the performance of multiple effect solar still (experimental results and simulation analysis under outdoor insulation for downward heating type stills), J. Jpn. Solar Energy Soc. 14 (6) (1988) 27-34.

[10] G.N. Tiwari, S.A. Lawrence, S.P. Gupta, Analytical study of multi-effect solar still, Energy Convers. Manag. 29 (4) (1989) 259-263.

[11] K. Ohshiro, T. Nosoko, T. Nagata, A compact solar still utilizing hydrophobic poly (tetrafluoroethylene) nets for separating neighboring wicks, Desalination 105 (1996) 207-217.

[12] B. Bouchekima, B. Gros, R. Ouahes, M. Diboun, Performance study of the capillary film solar distiller, Desalination 116 (1998) 185-192.

[13] H.M. Yeh, C.D. Ho, Energy and mass balances in multiple-effect upward solar distillers with air flow through the last-effect unit, Energy 25 (2000) 325-337.

[14] H. Tanaka, T. Nosoko, T. Nagata, A highly productive basin-type - multiple-effect coupled solar still, Desalination 130 (2000) 279-293.

[15] H. Tanaka, Y. Nakatake, A vertical multiple-effect diffusion-type solar still coupled with a heat-pipe solar collector, Desalination 160 (2004) 195-205.

[16] H. Tanaka, Y. Nakatake, A simple and high productive solar still: a vertical multipleeffect diffusion-type solar still coupled with a flat plate mirror, Desalination 173 (2005) 287-300.

[17] K. Fukui, T. Nosoko, H. Tanaka, T. Nagata, A new maritime lifesaving multiple-effect solar still design, Desalination 160 (2004) 271-283.

[18] T. Nosoko, T. Kinjo, C.D. Park, Theoretical analysis of a multiple-effect diffusion still producing highly concentrated seawater, Desalination 180 (2005) 33-45.

[19] T.L. Chong, B.J. Huang, P.H. Wu, Y.C. Kao, Multiple-effect diffusion solar still coupled with a vacuum-tube collector and heat pipe, Desalination 347 (2014) 66-76.

[20] B.J. Huang, T.L. Chong, P.H. Wu, H.Y. Dai, Y.C. Kao, Spiral multiple-effect diffusion solar still coupled with vacuum-tube collector and heat pipe, Desalination 362 (2015) 74-83.

[21] T. Rajaseenivasan, K.K. Murugavel, T. Elango, R.S. Hansen, A review of different methods to enhance the productivity of the multi-effect solar still, Renew. Sust. Energ. Rev. 17 (2013) 248-259.

[22] H. Tanaka, Theoretical analysis of a vertical multiple-effect diffusion solar still coupled with a tilted wick still, Desalination 377 (2016) 65-72.

[23] H. Tanaka, Y. Nakatake, Outdoor experiments of a vertical diffusion solar still coupled with a flat plate reflector, Desalination 214 (2007) 70-82. 